\title{
Who is to blame? Perspectives of caregivers on barriers to accessing healthcare for the under- fives in Butere District, Western Kenya
}

\author{
Antony S Opwora ${ }^{1 *}$, Ahmed MR Laving ${ }^{2}$, Lambert O Nyabola ${ }^{3}$ and Joyce M Olenja ${ }^{3}$
}

\begin{abstract}
Background: Kenya, like many developing nations, continues to experience high childhood mortality in spite of the many efforts put in place by governments and international bodies to curb it. This study sought to investigate the barriers to accessing healthcare services for children aged less than five years in Butere District, a rural district experiencing high rates of mortality and morbidity despite having relatively better conditions for child survival.
\end{abstract}

Methods: Exit interviews were conducted among caregivers seeking healthcare for their children in mid 2007 in all the 6 public health facilities. Additionally, views from caregivers in the community, health workers and district health managers were sought through focus group discussions (FGDs) and key informant interviews (KIs).

Results: Three hundred and ninety-seven respondents were surveyed in exit interviews while 45 respondents participated in FGDs and Kls. Some practices by caregivers including early onset of child bearing, early supplementation, and utilization of traditional healers were thought to increase the risk of mortality and morbidity, although reported rates of mosquito net utilization and immunization coverage were high. The healthcare system posed barriers to access of healthcare for the under fives, through long waiting time, lack of drugs and poor services, incompetence and perceived poor attitudes of the health workers. FGDs also revealed wide-spread concerns and misconceptions about health care among the caregivers.

Conclusion: Caregivers' actions were thought to influence children's progression to illness or health while the healthcare delivery system posed recurrent barriers to the accessing of healthcare for the under-fives. Actions on both fronts are necessary to reduce childhood mortality.

\section{Background} Introduction

About 20 million children die every year, often from preventable causes such as acute respiratory tract infections, diarrhoea, measles, malaria and malnutrition $[1,2]$. Despite decades of impressive gains in the reduction of childhood mortality, many African nations have started to experience a reversal of these gains [1], sending fears among health experts that the fourth Millennium Development Goal (MDG) which aims to reduce childhood mortality by two-thirds by the year 2015 [3], may not be realized. Kenya has actually seen a reduction in the under five child mortality from 115 per 1000 live births

\footnotetext{
* Correspondence: aopwora@nairobi.kemri-wellcome.org

'Kenya Medical Research Institute/Wellcome Trust Research Programme, P.O. Box 43640-00100, Nairobi, Kenya

Full list of author information is available at the end of the article
}

in 2003 [4], to 74 per 1000 in 2008/9 [5]. Yet mortality remains well above the target set in the fourth MDG of about 30 per 1000 by 2015 .

Numerous efforts have been put in place to reduce childhood mortality including the traditional vertical, disease-specific programs which have claimed a number of successes for example, the widespread acceptance and use of oral rehydration therapy in treating diarrhoeal diseases [6] and the increase in immunization coverage in several countries. The biggest challenge however has been with the burden they place on existing health systems and perhaps, the worst of all concerns has been the fragmented management of a child with multiple infections or health conditions $[7,8]$.

The Integrated Management of Childhood Illnesses (IMCI) was developed and promoted by World Health Organization (WHO) and United Nations Children

\section{Biomed Central}


Fund (UNICEF) starting in the 1990's to try and mitigate some of these concerns. However, coverage is still very low, a situation attributed to lack of financial and human resources, and poor working conditions with high turnover of health workers [9] in many of the developing nations. The success of IMCI strategy in reducing childhood mortality in Kenya remains to be realized [10]. Just as in several other studies [11-13], a report evaluating the implementation and effects of IMCI recommended free access to health as a major booster to freeing barriers to health [14]. On the other hand, socio-cultural barriers to accessing health care for children through perceptions of poor quality services [15] may be playing even a bigger role. Although the health facilities may be accessible in terms of geographical and economic aspects, the services being offered might not be acceptable to caregivers of children, thus serving as a barrier.

Most of the available evidence on access barriers has been documented in hospital settings with a bias on assessing infrastructure, drugs and other medical supplies and gathering views of health personnel and managers about problems of childhood mortality. New evidence is therefore needed from caregivers who are effectively barred from accessing healthcare and also from those who experience the shortcomings of the health system.

Healthcare, as used in this study encompassed the care and provision of services that help individuals achieve an optimal state of well-being, in any setting or stage in the human life cycle [16], to include the promotive, preventive and curative services. This includes the care provided both at home and at health facilities and involves everything that caregivers and health workers do for children to promote their well-being. A broad definition of access to healthcare, which draws on the works of Obrist et al [17] has therefore been used. In this study, we assessed some of the barriers to accessing healthcare both in terms of care (not) provided by caregivers and their social contexts and within the health delivery system. The main objective was to determine the perceptions and practices of caregivers concerning childhood illnesses; and identify the most important barriers to accessing health care in Butere District.

\section{Methods}

\section{Study Setting and Population}

Butere District was carved out of the larger ButereMumias District, which was previously part of Kakamega District in Western Kenya. The district is typically poor and rural with very high morbidity and mortality indicators. Its location in a high potential agricultural zone with conducive climatic conditions for productive livelihood has not helped in alleviating the poverty levels or improving the health of its inhabitants.
At the time of the study, Butere had a population of 111,637 people with public health facilities comprising of one district and one sub-district hospitals, 2 health centres and 2 dispensaries [18]. Informal health care providers consisting of herbalists, traditional medicinemen, hawkers, traditional birth attendants, medical practitioners, and drug shops, many of whom were unlicensed, were also providing care. There was also a heavy presence of licensed private clinics operated by clinical officers and different cadres of nurses. The study focused on caregivers of children aged less than five years. The under-fives were chosen because they form part of the population that is most vulnerable to underlying conditions which determine the general health outlook of the population.

Being a relatively new district, data on health indicators were not available however, according to the KDHS 2003, Western Province within which the district lies, had an under-five mortality rate of 144 per 1000 live births while the vaccination rate was 50\% [4], a whole ten percentage points below the national average. The KDHS 2008/9 report shows that under-five mortality has dropped by $15.9 \%$ to 121 per 1000 live births in the province, which is the second highest rate in the country (after Nyanza Province) and way above the national average of 74 per 1000 live births [5]. The same report also shows marked improvements in the vaccination coverage which, according to the report stands at $73 \%$.

\section{Study Procedures}

This was a descriptive cross-sectional study of caregivers of children aged below five years in Butere District. Quantitative data were collected between May and August 2007 among the caregivers attending Mother \& Child Health $(\mathrm{MCH})$ clinics at all the six public health facilities within the district. Each facility was allocated a proportionate number of caregivers depending on the average outpatient attendance within the month preceding the study. We aimed for an overall sample size of 385, derived from World Health Organization's formula for comparing proportions [19]. Systematic sampling was used to select caregivers who satisfied the inclusion criteria for exit interviews. During health talk sessions in the mornings, the strategy for randomly selecting the allocated number of respondents for the facility for that day was decided. For example, if the facility was allocated 10 caregivers for interview on that particular day and 50 attended the health talk morning sessions, then every fifth $\left(5^{\text {th }}\right)$ caregiver leaving the facility would be approached for interview. Only clients seeking outpatient preventive, promotive and curative services in the $\mathrm{MCH} / \mathrm{Child}$ welfare clinics, who consented, were interviewed. Caregivers attending the health facility later in the day replaced selected caregivers who were excluded 
in the morning. Quantitative data were collected on socio-demographic characteristics of caregivers in addition to information about their practices and experiences while seeking care for their sick children. Further, we enquired about their recommendations on how to improve access to health care for children aged below five years.

Qualitative data were collected concurrently with quantitative data through Focus Group Discussions (FGD) with community members from different divisions of the district. Four FGDs were held; one in each division, to capture a diverse range of opinions from the general community. Participants were recruited through community gate keepers including church leaders $(\mathrm{n}=$ 2 ) and women's group leaders $(\mathrm{n}=2)$, who invited mothers with children aged 5 years and below for a general discussion about their health. Discussions were conducted in settings within the community and at times agreed in advance with participants to ensure that participants felt as comfortable and free as possible. Each FGD consisted of between 6 and 12 caregivers with two trained enumerators to lead the discussions and to take notes. The key aspects addressed by FGDs included caregivers' perceptions of the key health problems affecting their children, their practices regarding health care for the children, experiences while seeking health care and what changes they thought were important to improve access to health care.

In addition to the FGDs described above, key informant interviews were also conducted with a district level health manager, referred to as the District Medical Officer of Health (DMOH), nurses and clinical officers working directly with the children and a traditional healer to get their perspectives of what they considered to be important caregiver and health system barriers to healthcare for the under fives, and how these barriers might be overcome.

This study was approved by the Kenyatta National Hospital/University of Nairobi Ethics Review Committee and the Ministry of Education, Science and Technology. Each interviewee received full information about the study and was asked if he/she was willing to participate before the interview began. For FGDs and individual interviews, informed consent processes included seeking permission to tape-record the proceedings. Consent was written for individual interviews and verbal for FGDs.

\section{Data Analysis}

Quantitative data were entered into a computer using Epi-Info database and analyzed using the Statistical Package for Social Sciences version 14.0 (SPSS $^{\odot}, 1989$ 2005). During the FGDs and key informant interviews, notes were taken and - where possible - discussions were taped-recorded. Notes and recordings were later transcribed and where necessary translated into English. Manual analysis of the discussions was done by reading through the transcripts and extracting similar parts of the transcripts into broad themes relevant to the study objectives. Themes were identified both inductively and deductively. Initial themes were based on the interview guide questions, but new themes were identified over the course of reviewing the data. Triangulation of data was used in the analytical process. Qualitative results are presented alongside the quantitative data wherever possible.

\section{Results}

\section{Socio-demographic Profile of Respondents}

A total of 397 respondents were interviewed with the greatest proportion being at the Butere District Hospital (25.7\%) followed by Shisaba (24.7\%) and Shimukoko (16.9\%) dispensaries. Shikunga and Shiraha health centres had $11.8 \%$ and $11.6 \%$ respondents, respectively. The Manyala SDH had the least number of respondents (9.3\%). Forty respondents participated in four focus group discussions while 5 key informants were interviewed at various locations.

Table 1 shows the socio-demographic characteristics of exit interviewees. Out of the 397 respondents, the majority (97.7\%) comprised biological mothers, whereas only $2.3 \%$ (9) were males, comprising of 8 biological fathers and 1 grandfather. A majority (61.2\%) of the caregivers fell within the 20-29 years age-group. At least $13(3.3 \%)$ respondents were aged below 18 years. Twelve (3\%) respondents who did not know their age were excluded from further analyses requiring this variable.

Figure 1 presents the age distribution of the caregivers' children. The mean age of the children was 16.6 months (Standard Deviation (SD): 15.7) with median age of 10 months (range $1-60$ ). Slightly over a half (53.5\%) of the children with the caregivers were females giving a male to female ratio of 1:1.15.

\section{Disease Profile of Study Children and Caregivers' Perceptions and Practices Regarding their Children's Health and IIInesses}

Thirty-four percent of the children were seeking routine immunization services on the interview day. Among the 256 ill children, $30.7 \%$ were reported to be suffering/ have suffered in the last two weeks prior to the survey, from malaria or acute febrile illness; $17.8 \%$ from respiratory tract infection; 8.8\% from a skin disorder; and 8.5\% from diarrhoeal diseases. The caregivers were then asked to grade the seriousness of their children's illnesses. It was beyond the scope of this study to confirm either the diagnosis or the severity of the illnesses as judged by caregivers. Almost a half (49\%) of the respondents said that their children's illnesses were severe 
Table 1 Socio-demographic Data of the Respondents

\begin{tabular}{ll}
\hline Characteristic of Respondents & Percentage \\
\hline Gender $(\mathbf{n}=\mathbf{3 9 7})$ & 97.7 \\
Female & 2.3 \\
Male & \\
\hline Age $(\mathbf{n}=\mathbf{3 9 7})$ & 9.3 \\
Below 20 & 61.2 \\
$20-29$ & 22.2 \\
$30-39$ & 4.0 \\
$40-49$ & 0.3 \\
50 \& Above & 3.0 \\
Don't Know Age &
\end{tabular}

\begin{tabular}{ll}
\hline Relation with the Child $(\mathbf{n}=\mathbf{3 9 7})$ & \\
Mother & 95.7 \\
Father & 2.0 \\
Grandparent & 2.3 \\
\hline Marital Status ( $\mathbf{n}=\mathbf{3 9 6})$ & \\
Married, Monogamous & 83.1 \\
Married, Polygamous & 8.3 \\
Single Parent & 7.3 \\
Divorced/separated/widowed & 1.3 \\
\hline Educational Attainment $(\mathbf{n}=\mathbf{3 9 7})$ & \\
None & 5.8 \\
Primary Incomplete & 48.1 \\
Primary Complete & 32.2 \\
Secondary & 11.1 \\
Tertiary & 2.8 \\
\hline
\end{tabular}

\begin{tabular}{ll}
\hline Employment Status $(\mathbf{n}=\mathbf{3 9 2})$ & 33.7 \\
Unemployed & 20.2 \\
Trader & 24.2 \\
Peasant Farmer & 15.8 \\
Self Employed & 5.6 \\
Formally Employed & \\
\hline Level of Income $(\mathbf{n}=\mathbf{3 9 7})$ & 69.6 \\
Less than Ksh 5,000 & 30.4 \\
Ksh 5,000 and above &
\end{tabular}

while $38 \%$ said the illnesses were not severe. Only $13 \%$ thought the illnesses were very severe. Bivariate analysis showed that none of the maternal characteristics (age, parity, marital status, income, education and occupation), nor the child's age and gender, were associated with the caregivers' perception of the child's illness being severe or very severe. Only children with complaints other than malaria/febrile illness were more likely to be perceived as being severely or very severely ill $(68.4 \%$ versus $57.3 \%$; $\mathrm{p}=0.013)$. As shown in Table 2 , regression analysis using these caregiver and child characteristics revealed that a child with malaria/fever had only about half the chance of being perceived as severely or very severely ill compared to a child with other illnesses (Odds Ratio $(\mathrm{OR})=0.469$; Confidence

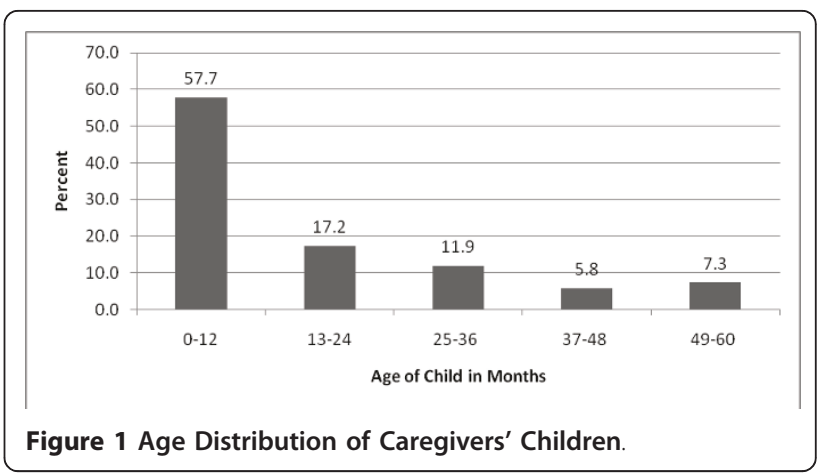

Interval $(\mathrm{CI})=0.273-0.805 ; \mathrm{p}=0.006)$. The other child and caregiver characteristics were not statistically significant.

Caregivers were asked about what actions they took when they first noticed their child was ill. Their responses are summarized in Table 3 which shows that the most common first action was to buy drugs from shops (53.1\%), while private hospitals were the least utilized (1.2\%). The type of first action taken was disaggregated into two groups of those caregivers who bought drugs from the local shop/kiosk and those who took their children to any health facility. The caregiver characteristics showed no statistically significant association with actions taken.

The data also show that $11.3 \%$ of caregivers reported not taking any action. Qualitative data revealed that caregivers sometimes failed to take their children for treatment due to reasons ranging from lack of money to finance transportation and user fees at facilities, past experiences with poor services offered and a failure to appreciate the severity of illnesses. During FGDs, caregivers reported that certain illnesses were commonly taken to traditional healers. Although the exit interviews revealed a low utilization of the traditional healers (6.3\%), the impression created by FGD participants was that traditional healers were a widely consulted group of practitioners who continued to hold a place in determining the fate of certain groups of children with particular illnesses whose nature we could not verify. To illustrate this point, a few quotes from different FGDs are given below:

"One can give birth to a baby with certain teeth in the mouth. If you take to the hospital, the doctors don't know how to remove these teeth. One has to take to a traditional doctor; there is a way in which they cut them"

"A child can be small, he can be eating but the body is just dry. There are doctors, who hold the baby in a certain way, then they pierce the body between the breast and ribs, they apply something and the body of the child returns [improves]. And this, if you take to the hospital, there is nothing they will do," 
Table 2 Logistic regression analysis: caregivers' opinion on the severity of child's illness

\begin{tabular}{|c|c|c|c|c|}
\hline Independent Variable $^{1}$ & $\begin{array}{c}\text { Illness Severe/Very Severe } \\
\text { Number (\%) }\end{array}$ & Odds Ratio & 95\% Confidence Interval & p-value \\
\hline \multicolumn{5}{|l|}{ Characteristics of Caregiver } \\
\hline \multicolumn{5}{|l|}{ Age $(n=256)$} \\
\hline 20 years \& below* & $24(61.5)$ & 1 & $0.410-2.935$ & 0.855 \\
\hline 21 years \& above & $133(61.3)$ & 1.096 & & \\
\hline \multicolumn{5}{|l|}{ Parity $(n=234)$} \\
\hline 1 - 2 children* & $63(58.9)$ & 1 & $0.447-1.659$ & 0.656 \\
\hline 3 children \& above & 77 (60.6) & 0.861 & & \\
\hline \multicolumn{5}{|l|}{ Marital Status $(n=264)$} \\
\hline All Other Statuses ${ }^{2} *$ & $141(63.5)$ & 1 & $0.754-3.790$ & 0.202 \\
\hline Monogamy & $22(52.4)$ & 1.691 & & \\
\hline \multicolumn{5}{|l|}{ Income $(n=253)$} \\
\hline Below Ksh. $5000^{*}$ & $108(60.7)$ & 1 & $0.325-1.216$ & 0.168 \\
\hline Ksh. 5000 \& above & $51(68.0)$ & 0.629 & & \\
\hline \multicolumn{5}{|l|}{ Education $(n=263)$} \\
\hline Primary \& Below* & $142(64.0)$ & 1 & $0.905-4.790$ & 0.084 \\
\hline Secondary \& Above & $20(48.8)$ & 2.082 & & \\
\hline \multicolumn{5}{|l|}{ Occupation $(n=261)$} \\
\hline Unemployed* & $57(61.3)$ & 1 & $0.766-1.508$ & 0.676 \\
\hline Employed/Trader/Farmer & $106(63.1)$ & 1.075 & & \\
\hline \multicolumn{5}{|l|}{ Characteristics of Child } \\
\hline \multicolumn{5}{|l|}{ Age $(n=264)$} \\
\hline 6 months \& below* & $27(56.3)$ & 1 & $0.270-1.289$ & 0.185 \\
\hline Above 6 months & $137(63.4)$ & 0.590 & & \\
\hline \multicolumn{5}{|l|}{ Gender $(n=259)$} \\
\hline Male* & $73(61.3)$ & 1 & $0.660-2.162$ & 0.557 \\
\hline Female & $86(61.4)$ & 1.195 & & \\
\hline \multicolumn{5}{|l|}{ Complaint $(n=253)$} \\
\hline Non-Malaria/Febrile IIIness ${ }^{3 *}$ & $67(57.3)$ & 1 & $0.273-0.805$ & 0.006 \\
\hline Malaria/Febrile IIIness & $93(68.4)$ & 0.469 & & \\
\hline
\end{tabular}

${ }^{1}$ All variables entered in the first step

${ }^{2}$ Includes: polygamous marriage, single parent, divorced or separated and widowed

${ }^{3}$ Non-Malaria/Febrile Illnesses: respiratory tract infections/cough, diarrhoea, and skin diseases

*Baseline group

"Ebikhokho, must also be taken to the [traditional healer] who cuts the baby for the child to be well. If you take the child with ebikhokho to the hospital he will die, especially if they are injected,"

The study found that caregivers follow interventions already in place to prevent childhood illnesses such as the use of mosquito nets and immunization, as well as breastfeeding. For instance, a majority of the children (80.6\%) was reported to have spent the previous night under a mosquito net. Only $19.4 \%$ reported their child had not slept under a mosquito net. Among the 77 respondents whose children had not used a mosquitonet the previous night, 32 (41.6\%) reported not owning any mosquito net at home. Further analysis showed that the caregiver's age, marital status, education level and occupation and the child's age and gender were significantly associated with the child sleeping under a mosquito net. Caregivers' income level and parity did not show any statistical significance in predicting a child's mosquito net use. In order to control for confounding, stepwise logistic regression analysis was carried out and the results showed that if the caregiver was in a monogamous marriage, then their child was more than twice as likely to have slept under a net than those of other marital statuses (OR: 2.702; CI: $1.343-5.434 ; \mathrm{p}=0.005)$; and if the caregiver was employed or was a trader, then the child was almost twice as likely to have slept under a net (OR 1.851; CI 1.285 - 2.664; $\mathrm{p}<0.001)$. The results also showed that the younger children (aged less than 6 months) and boys were less likely to have slept under a net than their older siblings and the girls. 
Table 3 The First Action Taken for a Sick Child $(n=256)$

\begin{tabular}{lll}
\hline Action & Frequency & Percent \\
\hline Bought medicine from shop & 136 & 53.1 \\
Took child to govt. hospital & 68 & 26.6 \\
Took child to private hospital & 3 & 1.2 \\
Took child to traditional healer & 16 & 6.3 \\
Other actions & 4 & 1.6 \\
Took no action & 29 & 11.3 \\
\hline Total & $\mathbf{2 5 6}$ & $\mathbf{1 0 0 . 0}$ \\
\hline
\end{tabular}

In regard to immunization, a majority of the respondents (90.2\%) had the "Road to Health" card in which the health workers record vaccinations administered to the child. A cross-check of these cards revealed that up to $97.8 \%$ of them were up to date with vaccinations appropriate for age. Almost all the caregivers without cards for their children said that their children's vaccination statuses were up to date.

Caregivers were also asked about their opinions on the length of exclusive breastfeeding on the mother's breast milk before a child is introduced to any other form of supplementary feeding. Their responses as summarized in Figure 2 show that $78.7 \%$ started supplementation within the first three months of life and almost a half $(47.7 \%)$ started before the end of the first month. A majority of FGD discussants said it was common practice to start supplementation very early in the child's life in this area. Further probing revealed various reasons for this practice:

"It depends on the type of child. Some come out of the womb when they are very hungry and cry a lot. So these must be given food almost immediately"

A majority (98\%) of exit interviewees continued breastfeeding during their child's illness, a fact that was corroborated in qualitative interviews where participants revealed that mothers knew they should continue to breastfeed if the child was ill, but the practice was dictated by the type of illness. For instance, if the child was vomiting or lost appetite or had a particular oral

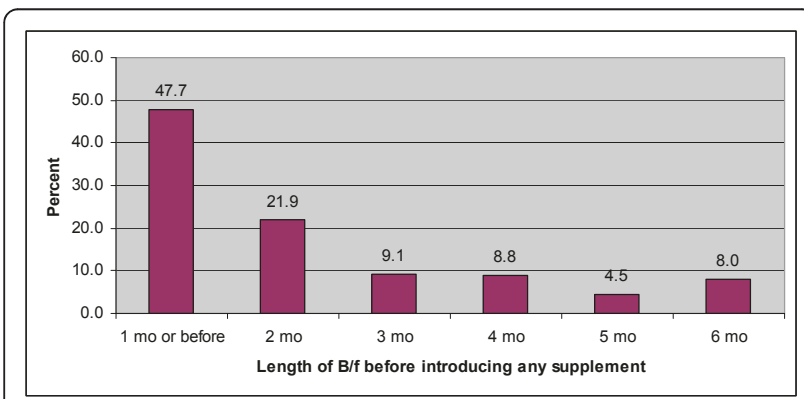

Figure 2 Respondents' Opinions on Length of Exclusive Breastfeeding. pathology referred to locally as "obuyindi", they would usually stop breastfeeding until the child recovered.

"We cannot force them to breastfeed when they have no appetite"

"Milk is not good when a child is vomiting and has diarrhoea. We normally stop and give ORS first before we continued to breastfeed"

\section{Perceptions of Health Care}

The single most experienced problem at the health facilities mentioned by $78.4 \%$ of all respondents was the long waiting time. Other problems mentioned included services not being up to expected standards (poor services) (5.8\%), lack of drugs (9.6\%) and unfriendly or rude staff (6.2\%).

We further investigated which independent variables were more likely to predict whether a caretaker would report having experienced problems at a health facility (Table 4). The results revealed that caregivers' income and education level were the strongest predictors of their reporting problems experienced at health facilities. About $80.2 \%$ of those who earned 5,000 shillings and above vs. $63.2 \%$ who earned less, and $80.4 \%$ of caregivers with secondary or higher education level vs. $65.8 \%$ of those with lower education level, reported having experienced problems at the health facilities. These differences were highly statistically significant with $\mathrm{p}=$ 0.001 and 0.031 for income and education status, respectively. Although there was a ten percentage point difference between the two marital status groups in reporting problems experienced at health facilities (monogamous $66.0 \%$ and other marital statuses $76.1 \%$ ), this difference was not statistically significant.

Opinions of FGD participants on whether the health system acted as a barrier to accessing healthcare were varied, with overall consensus being on the issues of understaffing and lack of drugs as the key barriers that forced them to seek alternative treatments for example, from traditional medicine men, herbalists, and hawkers. In some of the FGDs, the caregivers narrated their experiences at the hands of health staff, whom they thought acted rudely or unprofessionally as a result of being overworked from understaffing. On the other hand, one KI interviewee said that the health system did not pose a barrier but that it was the caregivers who failed to understand the system. There was agreement also on the "good side" of the health care system, which cast a good image on preventive aspects of care, for example, immunization and family planning and a bad one for curative departments. Overall, discussants were of the opinion that the curative departments were the worst staffed hence the few members of staff could not give adequate or expected care. This was best illustrated by one discussant who said: 
Table 4 Characteristics of those who reported experiencing problems at health facility

\begin{tabular}{|c|c|c|c|}
\hline Variable & $\begin{array}{l}\text { Number } \\
(\%)\end{array}$ & $\begin{array}{l}\text { Chi Square } \\
\text { Value }\end{array}$ & $\begin{array}{c}\mathrm{p}- \\
\text { value }\end{array}$ \\
\hline \multicolumn{4}{|l|}{ Caregiver characteristics } \\
\hline \multicolumn{4}{|l|}{ Age $(n=385)$} \\
\hline 20 years \& below & $42(64.6 \%)$ & 0.425 & 0.515 \\
\hline 21 years \& above & $220(68.8 \%)$ & & \\
\hline \multicolumn{4}{|l|}{ Parity $(n=350)$} \\
\hline 1 - 2 children & $112(70.4 \%)$ & 0.140 & 0.708 \\
\hline 3 children \& above & $131(68.6 \%)$ & & \\
\hline \multicolumn{4}{|l|}{ Marital Status $(n=396)$} \\
\hline All Other Marital Statuses & $51(76.1 \%)$ & 2.6 & 0.105 \\
\hline Monogamy & $217(66.0 \%)$ & & \\
\hline \multicolumn{4}{|l|}{ Income $(n=382)$} \\
\hline Below Ksh.5000 & $168(63.2 \%)$ & 10.805 & 0.001 \\
\hline Ksh.5000 \& above & $93(80.2 \%)$ & & \\
\hline \multicolumn{4}{|l|}{ Education $(n=395)$} \\
\hline Primary \& Below & $223(65.8 \%)$ & 4.680 & 0.031 \\
\hline Secondary \& Above & $45(80.4 \%)$ & & \\
\hline \multicolumn{4}{|l|}{ Occupation $(n=393$ ) } \\
\hline $\begin{array}{l}\text { Unemployed Employed/ } \\
\text { Trader }\end{array}$ & $\begin{array}{l}94(69.6 \%) \\
105(64.4 \%)\end{array}$ & & \\
\hline Farmer & $68(71.6 \%)$ & 1.683 & 0.431 \\
\hline \multicolumn{4}{|l|}{ Characteristics of the child } \\
\hline \multicolumn{4}{|l|}{ Age $(n=395)$} \\
\hline 6 months \& below & $75(67.0 \%)$ & 0.056 & 0.813 \\
\hline Above 6 months & $193(68.2 \%)$ & & \\
\hline \multicolumn{4}{|l|}{ Gender $(n=391)$} \\
\hline Male & $121(66.5 \%)$ & 0.042 & 0.837 \\
\hline Female & $141(67.5 \%)$ & & \\
\hline \multicolumn{4}{|l|}{ Complaint $(n=388)$} \\
\hline None & $97(73.5 \%)$ & 2.803 & 0.246 \\
\hline Non-Malaria/Febrile IIIness ${ }^{1}$ & $92(67.2 \%)$ & & \\
\hline Malaria/Febrile IIIness & $76(63.9 \%)$ & & \\
\hline
\end{tabular}

${ }^{1}$ Non-Malaria/Febrile Illnesses: respiratory tract infections/cough, diarrhoea, and skin diseases

"....the clinic side is ok, if you go there; you are attended to very well. On my side, there is a problem with treatment side. When you go with the child, you become the doctor. You will sit with the baby as you are asked about the baby. So you will tell him how the baby is coughing, how the temperature is high and so on, but there is no doctor [health worker] who will take their time to examine the baby in order to know whether it is the breast or the ribs [that have a problem], there is no good service here."

Despite all the foregoing, participants on the other hand portrayed serious misconceptions about how services are or should be offered at the health facilities.

"...But he will not examine the child. In case he does, then you know that the child is very serious and will die any time soon.... If he takes that thing [stethoscope] and places it on the child's chest, then that child will surely die".

Other notable misconception was the belief in injections as the best form of treatment, a fact that some key informants said was exploited by quacks, who treated all illnesses with injections. Additionally, the key informants said it was ignorance of the caregivers who failed to understand standard treatment protocols, resulting in unnecessary complaints. But the misconceptions were coupled with what caregivers viewed as incompetence of either health workers or the system:

".... but you yourself will have to be the doctor. You tell him how the child is and his work is to write in the book. Then he says: bring needle, bring syringe, [now] go for injection. But when it comes to the injection, maybe there is no drug, you are asked to go and buy. Now in this case, are you the one helping him or he is the one supposed to be helping you?"

Rudeness and harshness on the part of the health worker was also mentioned as a potential inhibitor of the caregivers wanting to continue to use the health facilities for care of their children. For instance in some FGDs, the caregivers had the following to say:

"At [our facility], just like one member has said, you can arrive with a child and then one nurse starts to scold you: 'Where have you been with this child?' You can also get annoyed because if you were not recognizing their services, you wouldn't have brought the child."

"You can go and find one who is very harsh and however sick your child is, you will just want to turn back and go home with them, saying 'Aah, if it is [this one] here today, let me go back home, I will only come back when somebody else is on duty'."

One of the KI questions was to find out whether the health system was acting as a barrier to accessing healthcare. While it was clear from discussions that the long waiting time, staff shortage, lack of drugs and unfriendly staff were some of the widespread occurrences within the study sites, suggestions on how to improve and manage certain aspects of the health care delivery system varied among the different groups of respondents, with those of exit interviewees being summarized in Table 5. While about 5.3\% of them specifically suggested supervision of staff, virtually all the KI interviewees were of the opinion that facility-level supervision of the staff to improve their performance and output would not work well.

"... also, it [supervision] won't work. Somebody like me, how can you supervise me? That one can't work. I will not do a good work when supervised. That one, I don't want to cheat you.... There are things that have been supervised somewhere [else] and they failed." 
Table 5 Respondents' Opinions on How to Improve Access to Healthcare for Under-fivest

\begin{tabular}{lll}
\hline Recommendation & Count & Percent \\
\hline Increase staff & 267 & 41.5 \\
Expand facility \& space & 125 & 19.4 \\
Avail drugs & 129 & 20.1 \\
Increase opening hours to 24 hrs & 45 & 6.9 \\
Train staff to be caring; Increase supervision & 34 & 5.3 \\
Install electricity, Provide water & 29 & 4.5 \\
Proper triage & 6 & 1.0 \\
Educate mothers on health care & 3 & 0.5 \\
Provide free nets & 3 & 0.5 \\
Improve roads & 2 & 0.3 \\
\hline Total & $\mathbf{6 4 3}$ & $\mathbf{1 0 0 . 0}$ \\
\hline
\end{tabular}

†Multiple response question

\section{Discussion}

\section{Study Limitations}

Conducting exit-interviews might have introduced a bias in presenting the views of only those that overcame certain barriers. However exit interviews were complemented by FGDs held in the community, and most results from the exit interviews concurred with issues raised in FGDs. Selection bias was therefore minimized. A community survey in the study area would have been more appropriate, but was not done due to time and financial constraints.

Some questions required a re-call time on the part of caregivers and answers to these might have been influenced by re-call bias. To minimize this, the interviewers were carefully trained to ask the questions exactly as written and to probe or provide explanations whenever it seemed that the interviewee did not understand.

\section{Socio-demographic Findings}

The main socio-demographic findings revealed a high proportion of female caregivers, which is not surprising in this setup as tradition has often bestowed the responsibility of child-caring on women, especially in the rural areas like Butere. The low educational attainment and high rate of unemployment suggest a low socio-economic status of the rural residents.

The youngest mother interviewed was reportedly 10 years and at least 13 respondents (mothers) were aged below 18 years. Under age mothers were not excluded from the study since we sought to determine those maternal characteristics important to children's survival. Capturing under-age mothers at the point of exit is in itself important data showing that first, childbearing starts early and second, children take care of other children in these settings, facts which in combination lead to high childhood morbidity and mortality.

Conversely, the fact that under-age mothers were interviewed might in itself raise ethical issues on their ability to give valid consent for interview. However, the fact that underage mothers take care of children can be argued to be raising both social capital and economic challenges for them to access healthcare, and so it was very important to get their side of the story. Additionally, these mothers are considered to be biologically underage, but socially, they are adults in the sense that the society has bestowed upon them the responsibility of bearing children and taking care of them. Whether they take on this responsibility successfully is the core issue of this inquiry. In this community, and indeed in many other African settings, one is considered an adult once they start bearing children, regardless of their biological age [20].

Kenya has been implementing youth-friendly services in some hospitals but this has been on a small scale, only targeting services related to HIV/AIDS and sexually transmitted infections. If these services were upscaled to primary-level facilities and incorporate a wider range of services including ANC, child welfare and family planning services, then the youth, who are potential young mothers could also access them, thereby reducing potential early motherhood and the related negative consequences.

\section{Perceptions and Practices of Caregivers Concerning Childhood Illnesses}

The ability of the caregiver to recognize a sick child has been associated with good response in terms of appropriate actions taken [21,22]. The first actions taken by caregivers in response to children's illnesses in this study were typical of other findings [21,23-27], suggesting that home-management of childhood diseases with shop-bought medicines is a common practice for most rural populations.

Exit interview data showed that a small proportion of caregivers sought the services of traditional healers, which corroborates results of an earlier survey done in Western Kenya [27]; but qualitative data suggest a different pattern. Specific childhood diseases such as ebikhokho, kilimi and obuyindi (whose nature we could not determine as even the health workers had differing views on what these really were) were commonly treated by traditional healers. Additionally, some health workers used to refer caregivers to the traditional healers whenever they suspected a child to be suffering from any of the listed illnesses. As such, the rate of utilization of the traditional healers is likely to be higher among the general population than that reported in this study. There is need for more research on why caregivers prefer traditional healers for certain childhood illnesses, and these might provide valuable lessons regarding the appropriate handling of mothers and children in this setting, and indeed in many other rural areas of Africa. 
The rate of mosquito-net usage is high compared to other studies done in Kenyan rural areas [11,28] where the rates were between $15 \%$ and $33 \%$. However, the factors predicting whether a child had slept under a mosquito net were similar. This high proportion may be a reflection of the true situation since the social marketing strategy by Population Services International (PSI) adopted nationally in 2001 may have achieved its program target [29], as indicated in Noor et al [11]. On the other hand, the self-selected sample of caregivers attending the health facilities may have been biased towards caregivers exposed to these interventions. However, this type of sample has been used previously with different results, although the timing was prior to mass distribution of ITNs [28]. Nationally, the country seems to be moving in the right direction, with under-five mortality declines being attributed partly to increased net coverage. The most recent demographic and health survey indicates that indeed, there have been improvements in ownership and use of ITNs countrywide with over half of children under age five sleeping under a net the night prior to the survey in 2008-09 compared with only 15 percent in 2003 [5]. It is therefore possible that mosquito net coverage within our study population is close to that indicated.

It was interesting to note caregivers' opinions on how long a child should be exclusively breastfed. More than $90 \%$ of caregivers felt it was appropriate to introduce supplementation earlier than recommended. Literature is replete with evidence of the advantages of exclusive breastfeeding for a period of at least 6 months, among them less morbidity from gastrointestinal infections and mothers experiencing prolonged lactational amenorrhea which is important in child spacing and better survival [30]. It is obvious that this community may never experience these benefits if the reported practice continues.

\section{Health System Barriers to Healthcare}

Among the barriers related to the health care delivery system mentioned explicitly by caregivers in exit interviews were long waiting time, lack of drugs and poor services, among others. During FGDs, additional barriers mentioned included incompetence and perceived poor attitude of the health workers. Conversely, FGDs also elicited widespread misconceptions among the caregivers about healthcare provision; these were confirmed by key informants reporting a widespread ignorance among the community members.

Experience of poor services was often viewed by caregivers as a constraint to seeking health services. Sobo et al, observed that the outcomes of experiencing access barriers contributed to suboptimal utilization of the health care system by the caregivers [31], an observation that has been confirmed by this study. Therefore, in the case where caregivers are not fully involved in the care of their children and are treated as illiterate observers or the health workers are rude or harsh, then access to healthcare for caregivers' children is greatly compromised. In other settings, some parents have had to deal in their own ways with what they saw as inexcusable incompetence among health workers [31]:

"I am expecting that the doctor is going to check the boy's ears, his temperature, I don't know - he doesn't do anything. He looks in, and asks how he is doing and I say 'The same', then he prescribes another thing ... or they go to their books and start reading, to see what they are going to prescribe, what does he have - if I had a book on my side, then I wouldn't need to come to the doctor."

\section{Conclusions}

This study aimed to investigate and document the barriers to access to healthcare services for children aged less than five years in Butere. The results complement similar studies done elsewhere which show that certain caregiverrelated attributes determine early childhood illness recognition and the taking of appropriate actions. New evidence from this study shows that the healthcare delivery system poses recurrent barriers to the accessing of healthcare for the under-fives, while caregivers expect more than what is offered in terms of quality of care. On the other hand, caregivers exhibited multiple misconceptions about the care that is offered at public health facilities.

For these reasons we would like to recommend firstly that the caregivers need to be empowered by the system comprising of local care managers in order to not only recognize but also to respond appropriately to illnesses in young children. Secondly, the MOH can deal with perennial staff shortages through, for example, incorporating the alternative health-care delivery practitioners (medicine men, quacks and TBAs among others) into the mainstream health-care, through training and systematic registration and recognition in collaboration with the Ministry of Social Services. At the national level, the government can implement a rural health facility-specific incentive to help retain qualified health professionals at the rural facilities, and this would improve service delivery at the primary health facilities.

Thirdly, the $\mathrm{MOH}$, district health managers, the Kenya Medical Supplies Agency (KEMSA) and other relevant authorities can combine efforts in ensuring that the quality of service delivery is up to at least the minimum expected standards. The $\mathrm{MOH}$ can ensure this through regular sharing of information on current practices; the district health managers can ensure that facilitative supervision and support takes place in their areas of jurisdiction; and KEMSA could improve its supply chain management and delivery of drugs and other medical supplies to health facilities. 
If these recommendations are implemented, we are likely to see a shift towards positive gains in the delivery of healthcare to the under-fives in the country, hence tackle the high mortality and pace towards achieving the fourth MDG.

\section{Acknowledgements}

ASO is a member of the KEMRI-Wellcome Trust Research Programme, which is supported by a grant from the Wellcome Trust (\#077092). At the time of this study, ASO was funded through a graduate student scholarship at the University of Nairobi (UoN). AMRL, LON and JMO are funded by the UoN. We wish to convey our gratitude to Mrs Mary Stocks (MS), whose invaluable contribution ensured the successful implementation of this study. The authors also wish to acknowledge the participants for providing useful information, and the research assistants Naomi Indosio, Carolyne Anekeya and Isaac Nandwa for their hard work during fieldwork. Neither UoN nor MS had any role in the design, conduct, analysis and interpretation of the study, and in the decision to submit the manuscript for publication

This paper is published with the permission of the Director of KEMRI.

\section{Author details}

${ }^{1}$ Kenya Medical Research Institute/Wellcome Trust Research Programme, P.O. Box 43640-00100, Nairobi, Kenya. ${ }^{2}$ University of Nairobi, Department of Paediatrics and Child Health, P.O. Box 19676-00202, Nairobi, Kenya. ${ }^{3}$ University of Nairobi, Department of Community Health, P.O. Box 1967600202, Nairobi, Kenya.

\section{Authors' contributions}

ASO conceived and designed the study, participated in data collection and analysis, and wrote the first draft of the manuscript and contributed to its revision. LON, JMO and AMRL contributed to data analysis, writing and revising the final manuscript. All authors read and approved the final manuscript.

\section{Competing interests}

The authors declare that they have no competing interests.

Received: 27 June 2010 Accepted: 3 May 2011 Published: 3 May 2011

\section{References}

1. The United Nations Children Fund: The State of the World's Children 2004 New York: UNICEF; 2003.

2. Black RE, Morris SS, Bryce J: Where and why are 10 million children dying every year? Lancet 2003, 361(9376):2226-2234.

3. United Nations. General Assembly 56th Session: Road map toward the implementation of the United Nations millenium declaration: report of the Secretary General. New York: United Nations; 2001.

4. Central Bureau of Statistics (CBS) [Kenya], Ministry of Health (MOH) [Kenya], ORC Macro: Kenya Demographic and Health Survey 2003. Calverton, Maryland; 2004.

5. Kenya National Bureau of Statistics (KNBS), ICF Macro: Kenya Demographic and Health Survey 2008-09. Calverton, Maryland: KNBS and ICF Macro; 2010.

6. Barber C, Masiello M: Oral Rehydration Therapy. Advanced Emergency Nursing Journal 1996, 18(3):21-26.

7. Bryce J, Victora CG, Habicht JP, Black RE, Scherpbier RW: Programmatic pathways to child survival: results of a multi-country evaluation of Integrated Management of Childhood IIIness. Health Policy Plan 2005, 20(Suppl 1):i5-i17.

8. Rowe AK, Onikpo F, Lama M, Cokou F, Deming MS: Management of Childhood Illness at Health Facilities in Benin: Problems and Their Causes. Am J Public Health 2001, 91(10):1625-1635.

9. DFID, UNICEF, USAID, WHO: The analytic Review of the Integrated Management of Childhood Illness Strategy: final report. Development DoCaAHa: World Health organization; 2004.

10. Mullei K, Wafula F, Goodman C: A case study of Integrated Management of Childhood IIIness (IMCI) implementation in Kenya. Nairobi: KEMRI-WT; 2008.
11. Noor AM, Omumbo JA, Amin AA, Zurovac D, Snow RW: Wealth, mother's education and physical access as determinants of retail sector net use in rural Kenya. Malar J 2006, 5:5.

12. Nordberg E, Holmberg S, Kiugu S: Exploring the interface between first and second level of care: referrals in rural Africa. Trop Med Int Health 1996, 1(1):107-111.

13. Peterson S, Nsungwa-Sabiiti J, Were W, Nsabagasani X, Magumba G, Nambooze J, Mukasa G: Coping with paediatric referral-Ugandan parents' experience. Lancet 2004, 363(9425):1955-1956.

14. Department for International Development, United Nations Children's Fund, United States Agency for International Development, World Health Organization: The analytic Review of the Integrated Management of Childhood IIIness Strategy: final report. Department of Child and Adolescent Health and Development: World Health organization; 2004

15. Schellenberg JA, Victora CG, Mushi A, de Savigny D, Schellenberg D, Mshinda $\mathrm{H}$, Bryce J: Inequities among the very poor: health care for children in rural southern Tanzania. Lancet 2003, 361(9357):561-566.

16. Daniels N: Just Health Care - studies in philosophy and health policy Cambridge: Cambridge University Press; 1985.

17. Obrist B, Iteba N, Lengeler C, Makemba A, Mshana C, Nathan R, Alba S, Dillip A, Hetzel MW, Mayumana I, et al: Access to health care in contexts of livelihood insecurity: a framework for analysis and action. PLoS Med 2007, 4(10):1584-1588

18. Ministry of Planning and National Development: Butere-Mumias District Development Plan. Nairobi: Government Printers; 2006.

19. World Health Organization: Field trials of health interventions in developing countries: a toolbox. 2 edition. London: Oxford University Press; 1996.

20. Dornbusch SM, Carlsmith JM, Gross RT, Martin JA, Jennings D, Rosenberg A, Duke P: Sexual development, age, and dating: a comparison of biological and social influences upon one set of behaviors. Child Dev 1981, 52(1):179-185.

21. Nsabagasani $X$, Jesca Nsungwa S, Kallander K, Peterson S, Pariyo G, Tomson G: Home-based management of fever in rural Uganda: community perceptions and provider opinions. Malar J 2007, 6:11

22. Taffa N, Chepngeno G: Determinants of health care seeking for childhood illnesses in Nairobi slums. Trop Med Int Health 2005, 10(3):240-245.

23. Abuya TO, Mutemi W, Karisa B, Ochola SA, Fegan G, Marsh V: Use of overthe-counter malaria medicines in children and adults in three districts in Kenya: implications for private medicine retailer interventions. Malar J 2007, 6:57.

24. Deressa W, Ali A, Enqusellassie F: Self-treatment of malaria in rural communities, Butajira, southern Ethiopia. Bull World Health Organ 2003, 81(4):261-268.

25. Hamel MJ, Odhacha A, Roberts JM, Deming MS: Malaria control in Bungoma District, Kenya: a survey of home treatment of children with fever, bednet use and attendance at antenatal clinics. Bull World Health Organ 2001, 79(11):1014-1023.

26. Molyneux CS, Mung'Ala-Odera V, Harpham T, Snow RW: Maternal responses to childhood fevers: a comparison of rural and urban residents in coastal Kenya. Trop Med Int Health 1999, 4(12):836-845

27. Mwabu GM: Health care decisions at the household level: results of a rural health survey in Kenya. Soc Sci Med 1986, 22(3):315-319.

28. Osero JS, Otieno MF, Orago AS: Maternal use of insecticide-treated nets in the prevention of malaria among children under five years in Nyamira district, Kenya. East Afr Med J 2005, 82(10):495-500.

29. PSI: Building a Net Culture in Kenya. Population Services International 2004.

30. Kramer MS, Kakuma R: Optimal duration of exclusive breastfeeding. Cochrane Database Syst Rev 2002, 1: CD003517.

31. Sobo EJ, Seid M, Reyes Gelhard L: Parent-identified barriers to pediatric health care: a process-oriented model. Health Serv Res 2006, 41(1):148-172.

\section{Pre-publication history}

The pre-publication history for this paper can be accessed here: http://www.biomedcentral.com/1471-2458/11/272/prepub

doi:10.1186/1471-2458-11-272

Cite this article as: Opwora et al: Who is to blame? Perspectives of caregivers on barriers to accessing healthcare for the under-fives in Butere District, Western Kenya. BMC Public Health 2011 11:272. 